\title{
From body part to applicative: encoding 'source' in Murrinhpatha
}

Rachel Nordlinger, University of Melbourne \& ARC Centre of Excellence for the Dynamics of Language

\begin{abstract}
Murrinhpatha (non-Pama-Nyungan, Australia) is typologically unusual in having a single applicative construction with the semantics of source/malefactive, but never benefactive (cf. Polinsky 2013). In this paper I discuss the development of this applicative from an incorporated body part meaning 'hand'. I show that the applicative developed from a reanalysis of the external possession construction; and that the applicative morphology developed from the incorporated body part, rather than from a verbal or adpositional source (Peterson 2006). This contributes to our understanding of the typology of applicative constructions and also highlights the value in exploring the complex verbal constructions of polysynthetic languages to inform our understanding of grammaticalisation possibilities.
\end{abstract}

\section{Key words}

applicative, noun incorporation, Australian languages, polysynthesis, source, malefactive

\section{Introduction}

Polysynthetic languages are characterised by their morphologically complex verbs, which can often express in a single word that which requires a multi-word sentence in non-polysynthetic languages (Fortescue, Mithun \& Evans 2017). As well as argument marking by way of bound pronominals, verbs in polysynthetic languages often also allow noun incorporation and a range of valency-changing and applicative operations, all tied up within a strongly bound templatic verbal structure (Fortescue, Mithun \& Evans 2017: 12-13). Polysynthetic languages can therefore provide a useful laboratory for investigating the interaction of different derivational morphological categories and the development of applicative morphology (Mithun 2017). In this paper I show how productive noun incorporation has led to the development of a typologically unusual applicative marker in the polysynthetic language Murrinhpatha, spoken in the Daly region of northern Australia. 
Illustrative examples of the Murrinhpatha data are given in (1) and (2). In (1) we see the occurrence of the incorporated body part - $m a$ - 'hand' in a productive construction which allows body parts to incorporate, and their possessors (or 'wholes') to be encoded as clausal objects. In (1) we see the 'whole' encoded with the $2 \mathrm{SG}$ object bound pronoun $-n h i-$. In (2) we see the same form - $m a$ - in an applicative function indicating the source of the action, which is encoded with the same object bound pronoun -nhi-. In the remainder of this paper I will argue that $-m a$ - in (2) is indeed an applicative which has developed directly from the incorporated body part in (1). ${ }^{1}$

mam-nhi-ma-purl

1SGS.HANDS(8).NFUT-2SGO-hand-wash

'I washed your hands.' (Walsh 1996: 329)

(2) nganam-nhi-ma-kut

1SGS.BE(4).NFUT-2SGO-APPL-collect

'I collected (the money) from you.' (RN 20070608-002:037) ${ }^{2}$

The construction in (1) is similar to what has been called external possession in the literature (Chappell \& McGregor 1996; Payne \& Barshi 1999), since it is the possessor that is encoded as the clausal argument (evidenced by the object $2 \mathrm{SG}$ bound pronoun -nhi-), rather than the body part. This external possession construction is only possible in Murrinhpatha with inalienably possessed body parts. Were the sentence to mean 'I washed your dog' the form of the verb would be as in (3): note

\footnotetext{
${ }^{1}$ As discussed in more detail in Section 2, these verbs are complex predicates, consisting of a classifier stem and a lexical stem which together provide the predicate semantics. In example (1), the classifier stem in first position in the verb classifies events that are done with the hands and is therefore glossed (do with) HANDS. It thus classifies the nature of the action, and its occurrence is completely independent of the incorporated body part -ma- 'hand', which refers to the actual body part of the object.

${ }^{2}$ Many examples in this paper are taken from my own fieldwork with Murrinhpatha speakers - such examples are marked with RN as part of the source code. Examples taken from other people's fieldwork or published sources are identified accordingly.
} 
that there is no incorporated body part, and the possessor is not marked in the verb with -nhi- since the possessed entity 'dog' now functions as the clausal object argument. Third singular objects are not marked in the Murrinhpatha verb - see Section 2 below - and so there is no object marking agreeing with 'dog'.

$\begin{array}{llll}\text { mam-purl } & k u & \text { were } & \text { nhinhi } \\ \text { 1SGS.HANDS(8).NFUT-wash } & \text { CLF:ANIM } & \operatorname{dog} & \text { 2SG } \\ \text { 'I washed your dog.' (constructed for illustration) }\end{array}$

The Murrinhpatha 'source' applicative discussed in this paper is typologically unusual in a number of respects. Firstly, it is the only applicative present in the language, and it is cross-linguistically unusual for a language to have a single applicative construction which is not used with benefactive semantics (Polinsky 2013, see also Peterson 2006: 41). Secondly, it is very unusual to have an applicative construction encoding 'source' at all - applicatives of this type are not mentioned in many typological discussions of applicatives (e.g. Peterson (2006)). Thirdly, as I will argue below, this applicative has developed out of the external possession construction shown in (1) and therefore provides evidence for an additional source for the grammaticalisation of applicatives beyond the more typical verbal and adpositional ones (Peterson 2006: 141).

This paper proceeds as follows. In Section 2 I provide a brief overview of Murrinhpatha and the parts of its grammar that will be important for the ensuing discussion, in particular the structure of the polysynthetic verb and the morphosyntax of objects, obliques and adjuncts; before turning to a discussion of noun incorporation in Section 3. In Section 4 I present the Murrinhpatha applicative construction and provide evidence supporting my analysis that it is distinct from the use of - $m a$ - as an incorporated body part. Having established that they are constructionally distinct, in Section 5 I address the relationship between the two constructions and argue that the applicative use has developed from the incorporated body part via the external possession construction. 


\section{Murrinhpatha overview}

Murrinhpatha is a non-Pama-Nyungan polysynthetic language of the Daly River region of northern Australia. It is spoken by around 2500 people, mainly located in the remote township of Wadeye (Port Keats) in the Northern Territory. It is still learned as a first language by children of the community and is the primary language of daily communication in Wadeye and surrounding communities. Initially, Murrinhpatha was assumed to be a language isolate (Tryon 1974), but more recently it has been shown to belong to the Southern Daly subgroup with Ngan'gityemerri (Green 2003). Broader relationships are as yet unestablished, but there are clear areal similarities with the Western Daly family, as discussed in Nordlinger (2017). Aspects of the grammatical structure of Murrinhpatha have been described by a number of researchers, most notably Walsh (e.g. 1976; 1996; 1997), Street (e.g. 1987; 1996), and more recently Blythe (e.g. 2009; 2013), Mansfield (e.g. 2014; 2016; 2019) and Nordlinger $(2010 ; 2011 ; 2015 ; 2017)$. The reader is referred to these works for more detailed discussion of the language more generally; in this section I present only the information relevant to understanding the development of the applicative construction.

Murrinhpatha shares many typological characteristics common to polysynthetic languages, including syntactically free clausal word order, and optionality of argument NPs. It is usually described as having relatively free word order at the clausal level (Walsh 1976); a small corpus study found that SV and OV are the most prevalent orders, but that all orders are possible and it is difficult to posit a default or basic word order (Mujkic 2013: 53). Argument NPs are regularly unexpressed: Mujkic found that $29 \%$ of verbal clauses in the corpus had no argument NPs at all, and only 3\% had both subject and object NPs overtly expressed (Mujkic 2013: 54-55). This means that clauses often consist of just a verb, and that external NPs for arguments are often not present. These properties of Murrinhpatha will be prevalent in the examples used throughout this paper.

\subsection{The verbal template}

Since Murrinhpatha is a polysynthetic language, the main locus of grammatical complexity lies with the verb. Verbs in Murrinhpatha, as with other Southern and Western Daly languages, are (mostly) complex predicates, made up of two 
discontinuous stem elements which together define the predicational semantics and argument structure. In related verb-coverb constructions in many other northern Australian languages (Wilson 1999; Schultze-Berndt 2000; McGregor 2002; Bowern 2014), these two stems are separate words: the 'inflecting' or 'finite' verb taking verbal morphology and argument marking, and the 'coverb' being generally unmarked. In Murrinhpatha these two elements are morphologically composed into a single word, as two distinct verbal stems. In this paper I will refer to them as the classifier stem (analogous to the 'finite verb' in analytic systems) and the lexical stem (analogous to the 'coverb' of other systems). Classifier stems form 38 distinct paradigms and are (synchronic) portmanteaux, marking also tense/mood and subject person and number. ${ }^{3}$

The basic templatic structure of the Murrinhpatha verb is shown in Table 1 (see Nordlinger $(2010 ; 2015)$ for more detailed discussion); the two stem elements are given here in italics, and the applicative marker, which is the focus of this paper, is shown in bold. The only truly obligatory slot in the verb is Slot 1 , since some verbs can consist of just a classifier stem (see (7) below). Most verbs are complex predicates, and so have slots 1 and 5 minimally filled (as in (4) and (5)), but as is clear from this template, it is possible for the two parts of the predicate to be separated by other morphological elements such as object and oblique marking (slot 2) (as in (6)) and incorporated body parts (slot 4). The applicative marker occurs in the same verbal slot as incorporated body parts; I return to this point in Section 4 below.

\begin{tabular}{|l|l|l|l|l|l|l|l|l||}
\hline 1 & 2 & 3 & 4 & 5 & 6 & 7 & 8 & 9 \\
\hline CS.SUBJ.TAM & $\begin{array}{l}\text { SUBJNUM/ } \\
\text { OBJ/OBL }\end{array}$ & RR & $\begin{array}{l}\text { IBP/ } \\
\text { APPL }\end{array}$ & LEXS & TAM & ADV & $\begin{array}{l}\text { SUBJNUM/ } \\
\text { OBJNUM }\end{array}$ & ADV \\
\hline
\end{tabular}

Table 1. Murrinhpatha verbal template ${ }^{4}$

\footnotetext{
${ }^{3}$ Although see Mansfield (2016) for a discussion of the partial regularities that can be identified within and across some of the paradigms, also Mansfield and Nordlinger (In Press).

4 Abbreviations used in this table are: CS 'Classifier stem'; SUBJ 'subject marking'; TAM 'tense/aspect/mood'; NUM 'number marking'; OBJ 'object marking'; OBL 'oblique marking'; RR 'Reflexive/Reciprocal marker'; IBP 'incorporated body part'; APPL ‘applicative'; LEXS 'lexical stem'; ADV 'adverbial marker'. Mansfield (2014) notes some variation in morph order on the right edge of this
} 
There are 38 different paradigms of classifier stems (Blythe, Nordlinger \& Reid 2007) and many hundreds of lexical stems, which combine with varying degrees of productivity to form complex predicates. The most productive lexical and classifier stems can be found in many different combinations. Other parts of the system are highly lexicalised, so that a particular lexical stem may combine with only a single classifier stem. The combination of the classifier stem and the lexical stem may be semantically compositional $(4,5)$ or noncompositional $(6)$, as shown in the examples below. ${ }^{5}$

(4)

$$
\begin{aligned}
& \text { nungarntirda } \\
& \text { nungam-rirda } \\
& \text { 3SGS.FEET(7).NFUT-push } \\
& \text { 'He kicked him.' } \\
& \text { (RN 20070531-002:016) }
\end{aligned}
$$

\author{
marntirda \\ mam-rirda \\ 3SGS.HANDS(8).NFUT-push
}

'He pushed him (with his hands).'

(RN 20070531-002:016)

(6)

\title{
mampunmardaraki
}

3SGS.HANDS(8).NFUT-3PLO-disappoint

'He disappointed them.' (Street \& Street 1989 \#mardaraki)

A minority of classifier paradigms (11 of 38) can occur as simple verbs (7), but the majority can only occur in conjunction with a lexical stem. Lexical stems can never occur as simple verbs.

\author{
(7) ngunungam \\ 1SGS.FEET(7).NFUT-now \\ 'I'm going.'
}

\footnotetext{
template, especially in the speech of younger speakers, but this variation doesn't affect the data being discussed in this paper.

${ }^{5}$ The semantics of the classifier stem paradigms has not been fully analysed, and traditionally paradigms have been referred to by a number. In this paper, I provide indicative glosses for classifiers wherever possible, but readers should be aware that these are merely placeholders for a proper semantic analysis. I also include the number of the paradigm in brackets, e.g. '(do with) HANDS(8)'.
} 


\subsection{Objects, obliques and adjuncts}

The second slot in the verbal template hosts object marking (8), although third singular objects are unmarked, as shown in (9).

(8) nakurl ba-nhi-ngkardu-nu

later 1SGS.SEE(13).FUT-2SGO-see-FUT

'I'll see you later.' (RN 20070607-002:022)

(9) nakurl ba-ngkardu-nu

later 1SGS.SEE(13).FUT-see-FUT

'I'll see him/her later.' (RN 20070607-002:022)

The second verbal slot is also the locus for oblique marking, which cross-references the recipient object of ditransitive verbs (11), the complement of semitransitive verbs (12) and also encodes a beneficiary with any verb (13-15).

$\begin{array}{lcl}\text { parram-na-mut } & k a r d u & \text { numi } \\ \text { 3PLS.POKE(19).NFUT-3SG.M.OBL-give } & \text { CLF:HUMAN } & \text { one }\end{array}$

'They gave them to one person.' (RN 20050715-001:065)

(12) bath ma-mpa-ngka-nu

wait 1SGS.HANDS(8).FUT-2SG.OBL-wait-FUT

'I'll wait for you.' (Joe Blythe, fieldnotes, pers. comm.)

(13) ngina-mpa-thi-nu

1SGS.HEAT(27).FUT -2SG.OBL-cook-FUT

'I'll cook (it) for you.' (RN 20070608-002:042)

(14)
ngarra nanthi
truck-te
pana punu-nga-nu
LOC CLF:THING
truck-AGT
RCGN 3SGS.FEET(7).FUT-1SG.OBL-FUT
'when that truck will come for me...' (RN 9-08TN-School-003.022)

\footnotetext{
${ }^{6}$ In this and other examples taken from Joe Blythe's work, I have changed the orthography to be consistent with the community-preferred orthography used in the rest of this paper.
} 
ma-mpa-berti-nu ngarra $d^{7}$

1SGS.HANDS(8).FUT-2SG.OBL-take-FUT home

'I'll take (him) home for you.' (RN 20070608-002:042)

Objects and obliques are marked with distinct sets of bound markers, as shown in Table 2 (see Nordlinger 2011 for further discussion).

\begin{tabular}{|l|l|l|}
\hline Person/number & OBJECT & OBLIQUE \\
\hline 1SG & $-n g i$ & $-n g a$ \\
\hline 1DU/PC (EXCL) & $-n g a n k u$ & $-n g a r r u$ \\
\hline 1PL (EXCL) & $-n g a n$ & $-n g a r r a$ \\
\hline 1INCL & $-n h i$ & $-n h e$ \\
\hline 2SG & $-n h i$ & - mpa \\
\hline 2DU/PC & $-n a n k u$ & $-n a r r u$ \\
\hline 2PL & $-n a n$ & $-n a r r a$ \\
\hline 3SG & {$[$ unmarked] } & -na (M) /-nge (F) \\
\hline 3DU/PC & - punku (NFUT)/-nku (else) & -pirru (NFUT) /-rru (else) \\
\hline 3PL & - pun (NFUT) /-n (else) & -pirra (NFUT) /-rra (else) \\
\hline
\end{tabular}

Table 2. Object and oblique markers

As discussed in Nordlinger (2011: 724), it is hard to find other morphosyntactic properties, besides the verbal marking in Table 2, that consistently distinguish object arguments from oblique arguments and adjuncts. Case marking on NPs is very minimal in Murrinhpatha. Direct object NPs (i.e. those cross-referenced with the object markers in Table 2) are always unmarked for case, as in the following, where the unmarked NP in bold is cross-referenced by an object marker in the verb (also in bold).

kardu wakal ngurdu-n-thukthuk-nu

CLF:HUMAN little 1SGS.SHOVE(29).NFUT-3PLO-send(RDP)-FUT

ngarra da-warda

home-NOW

'I'll send all these kids home now.' (RN 20070608-002:037)

\footnotetext{
${ }^{7}$ ngarra da (LOC CLF:PLACE) literally means 'to the place' but it is also an idiom meaning 'home', as in these examples.
} 


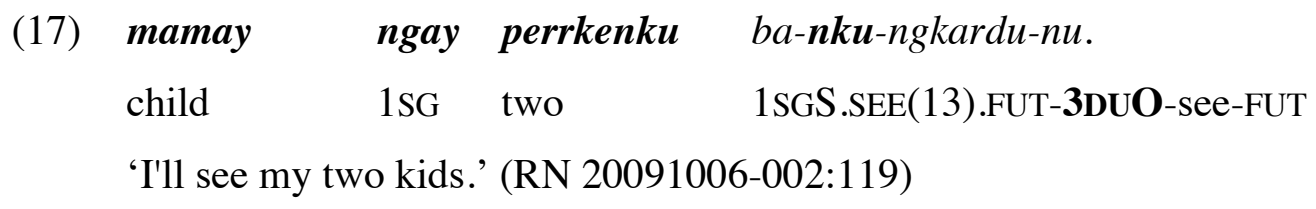

Oblique NPs, in contrast, may be marked with dative case as in (18), where the dative-marked NP in bold is cross-referenced with (bolded) oblique marking in the verb.

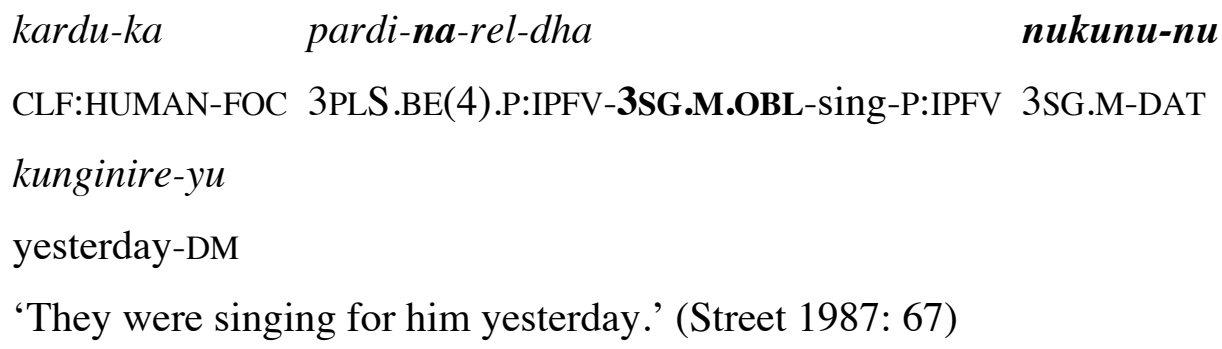

However, this dative case does not appear on all oblique NPs, and there are many examples in which NPs cross-referenced with oblique marking in the verb are unmarked for case, like objects. Consider (11) above, repeated here as (19), where kardu numi is an unmarked NP expressing recipient, and yet is marked on the verb with the oblique marker $-n a$.

\begin{tabular}{|c|c|}
\hline parram-na-mut & kardu \\
\hline 3PLS.POKE(19).NFUT-3SG.M.OBL-give & CLF:HUMAN \\
\hline
\end{tabular}

Location-related adjuncts are generally marked with the language's only preposition ngarra 'LOC', and are never cross-referenced with an oblique marker on the verb as shown in (20) and (21).

(20) $m i$ lawam ban-pak CLF:VEG flour 1SGS.17.NFUT-put.down LOC CLF:TREE 'I put the flour by the tree' (Street 1987: 65) 
(21)

nginanganthi

nginangam-thi

1SGS.HEAT(27).NFUT-cook LOC CLF:FIRE

'I cooked it in the fire.' (RN 20090930-002:079-84)

However, other types of adjuncts appear in bare NPs like objects, although they are not cross-referenced with object marking on the verb, as shown in (22) and (23).

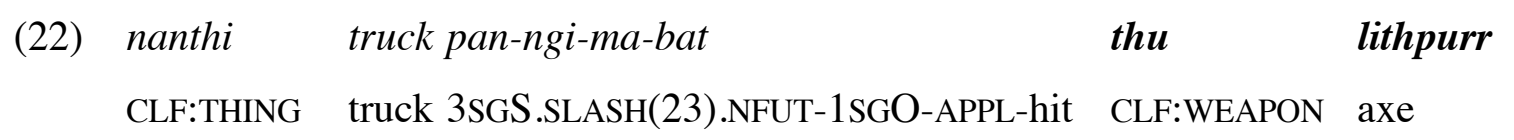

'He hit my truck with an axe.' (RN 20090930-002:079-84)

\begin{tabular}{llr} 
pumam-ngan-manpi & kardu & \multicolumn{2}{c}{ kunuwunu pangu } \\
3PLS.HANDS(8).NFUT-1PLEXCLO-help & CLF:HUMAN & old.women DIST \\
pumam-ngan-manpi & murrinh-ka & kanhi-wa \\
3PLS.HANDS(8).NFUT-1PLEXCLO-help & CLF:LANG-FOC & this-EMPH
\end{tabular}

'Those old women helped us, they helped us with this language.' (RN 908TN-School 003.024)

Thus, while it is true that all object NPs are unmarked for case, it is not the case that all unmarked non-subject NPs will correlate with object marking in the verb - it is possible for certain adjuncts to be unmarked, as in (22) and (23). Object markers, however, can only cross-reference an unmarked NP, and dative-marked NPs will always be crossreferenced with oblique markers in the verb. Nordlinger (2011) provides more detail about the identification of grammatical relations in Murrinhpatha.

Returning to discussion of the verbal template in Table 1, both object and oblique marking compete for slot 2 . When the object is $3 \mathrm{SG}$, there is no conflict as $3 \mathrm{SG}$ objects are unmarked in the verb and so slot 2 is available for oblique marking, as we see in (15) above, repeated here as (24). In this example the 3SG object is unexpressed.

ma-mpa-berti-nu

ngarra da

1SGS.HANDS(8).FUT-2SG.OBL-take-FUT home

'I'll take (him) home for you.' (RN 20070608-002:042) 
In other cases, where overt marking would be possible for both object and oblique, there does not seem to be a grammatical constraint on which one takes precedence for realisation in slot 2 . The two sentences below are equivalent, and equally grammatical - in (25a), the oblique is encoded in the verb and the object as an external NP, and in (25b) it is the reverse. ${ }^{8}$

\begin{tabular}{|c|c|c|c|}
\hline$(25 \mathrm{a})$ & ngay-warda & ma-na-berti-nu & nhinhi-yu \\
\hline & 1SG-TEMP & 1SGS.HANDS(8).FUT-3SG.M.OBL-take-FUT & 2SG-CLS \\
\hline
\end{tabular}
(25b) ngay-warda ma-nhi-berti-nu nukunu-nu 1SG-TEMP 1SGS.HANDS(8).FUT-2SGO-take-FUT 3SG.M-DAT 'I will take you for him.'

For a more detailed discussion of the Murrinhpatha verb, the reader is referred to Nordlinger $(2010 ; 2011 ; 2015)$ and Mansfield (2019). For the purposes of the present discussion, the key points of relevance are that direct objects are marked in the verb with object markers (when not 3SG, which are unmarked), and cross-referenced with unmarked NPs, while benefactives and other oblique arguments are cross-referenced with a distinct set of oblique verbal markers. In the next section, I turn to a discussion of incorporated body parts.

\section{Incorporated body parts}

Noun incorporation in Murrinhpatha is possible only with body parts (Walsh 1996; Forshaw 2011). Incorporated body parts are distinct bound forms that are often reduced or even suppletive when compared with the corresponding full nominals. There is a set of 35 incorporated body parts (IBPs) (Street 1987; Forshaw 2011), some examples of these incorporated forms and their corresponding nominal counterparts are given below.

\footnotetext{
${ }^{8}$ Thanks to Francella Bunduck and Bill Forshaw for providing these examples.
} 


\begin{tabular}{lll} 
Nominal & IBP & Gloss \\
mange & $-m a-$ & 'hand' \\
lamala & - mala- & 'shoulder' \\
miyernu & - gumu- & 'tail' \\
kamarl & $-n g k a-$ & 'eye' \\
pelpith & $-w e-/-p e-$ & 'head' \\
the & $-y e-/-t h e-$ & 'ear' \\
lawali & $-b u-$ & 'thigh/upper leg' \\
\multicolumn{2}{l}{ Table 3. Incorporated body parts and corresponding nominals }
\end{tabular}

Noun incorporation is found in a number of non-Pama-Nyungan languages of northern Australia (Evans 2017) and in almost all of the other languages in the Daly region (Nordlinger 2017). As can be seen in Table 3, some incorporated body parts have a clear formal relationship with the corresponding noun (-ma- and mange 'hand'; -mala- and lamala 'shoulder', etc.), while others show no formal correspondence (e.g. -bu- and lawali 'thigh/upper leg').

These incorporated body parts are used in a range of functions. In (26)-(29) the incorporated body part works in conjunction with the direct object marker in the verb to express the body part of the object (although recall that 3SG objects are unmarked, as in (29)). This construction is therefore a type of external (inalienable) possession construction (Payne \& Barshi 1999) in that the animate possessor is encoded as the direct object of the verb, and the possessum (the body part) is encoded separately, as an incorporated nominal. As shown in (28) and (29), the incorporated nominal can optionally be doubled with an unmarked external body part NP. ${ }^{9}$

\footnotetext{
${ }^{9}$ A reviewer asks whether this construction specifically denotes possession or whether it just marks affectedness, with the possessive meaning arising though translations into English. This is a complex question, and one that is beyond the scope of the present paper. However, I believe it is reasonable to treat it as an external possession construction since it conforms to the criteria for external possession constructions in the typological literature (e.g. Payne \& Barshi 1999). Furthermore, there is a large amount of research which shows a strong association between the semantics of affectedness and inalienable possessive constructions (Mithun 2001; Beaver 2011), so treating it as an external (inalienable) possessive construction doesn't preclude it also having the semantics of affectedness as well (as I suggest in Section 5).
} 
(26) mam-ngi-ma-yeth

3SGS.HANDS(8).NFUT-1SGO-hand-slice

'He cut my hand (with a knife).' (MP-20120730-RN01)

(27) dirran-ngi-me-thith $=$ dim

3SGS.WATCH(28).NFUT-1SGO-foot-stare=3SGS.SIT(1).NFUT

'She's staring at my feet.' (RN 20090930-002:079)

(28) (mange) mem-ma-yeth

hand 3SGS.HANDS:RR(10).NFUT-hand-slice

'He cut his own hand.' (RN 20070530-002:005)

(29) (nanthi pemarr) bangam-pe-rartal=pirrim

CLF:THING hair 3SGS.BASH(14).NFUT-hair-chop=3SGS.STAND(3).NFUT

'He was cutting (her) hair (while standing).' (RN 20070531-002:015)

Determining the grammatical function of the incorporated body part in these examples is not straightforward. The fact that the external body part NP appears in unmarked case in (28) and (29) is consistent with it being an object, as discussed in Section 2. This is further supported by the fact that these examples contrast with nonincorporated possessive constructions in which the body part appears as head of an unmarked NP modified by a pronoun marking possessor, as shown in (30).

ngungu-wirtpirt-nu

mange ngay

1SGS.32.FUT-remove.from(RDP)-FUT hand 1SG

'I'll remove (it) from my hand.' (RN 20090930-002:083)

However, the reflexive construction in (28) presents evidence that the incorporated body part cannot be a direct object, since it remains present in the reflexive 
construction, which is otherwise intransitive (Nordlinger 2011). The morphosyntactic properties of the external possession construction suggest that it would be best accounted for with a valency-increasing analysis in which the incorporated body part fills an additional grammatical function in the verb's argument structure, in this case secondary object, which remains unaffected by the reflexive operation in examples such as (28) (see, for example, Baker et al's (2010) analysis of noun incorporation in Wubuy). However, I leave the details of such an analysis for future research; providing a detailed syntactic analysis of the incorporated body part construction is not central to the goals of this paper. What is important for this paper is that the incorporated body part in these constructions is productively incorporated, it can be doubled by an external unmarked NP, and it refers to a body part of the patient/theme that is the direct object of the verb (Forshaw 2011).

Incorporated body parts can also be metaphorically and metonymically extended beyond the productive external possession construction exemplified above. Many of these semantically extended uses are discussed by Walsh (1996). Forshaw (2011) argues that these extended functions illustrate a distinct type of 'range' incorporation in which the incorporated nominal "either further specifies the process of the verb or denotes the domain of the process" (2011: 59), rather than referring to a part of the object argument (see also Harvey 1996; Wilson 1999). Thus, in these functions the incorporated body parts behave more like grammaticalised lexical prefixes which modify or situate the action of the verb (see for example Fleck (2006)). Examples include the following:

(31)

$\begin{array}{llll}\text { lithpurr } & \text { du-ngurru-pak } & \text { ngarra } & \text { palyirr } \\ \text { axe } & \text { 2SGS.17.FUT-side-put.down } & \text { LOC } & \text { stone }\end{array}$

'Put your axe beside the stone.' [not axe's side] (Walsh 1996: 349)

(32) nganam-marda-wu

1SGS.BE(4).NFUT-belly-lay

I laid them in the middle (or in an object) [not their middles] (Street and Street 1989 \#wu) 
These uses contrast with the external possession constructions above since the incorporated body part here does not refer to the patient/theme argument of the verb, but rather modifies the location of the action: ngurru in (31) does not refer to the side of the 'axe' (the theme), but rather 'the stone', which is where the object is being placed. Similarly, in (32), the incorporated noun 'belly' encodes the meaning of 'laying something inside', as opposed to referring to the bellies of the theme; the sentence does not mean 'I laid their bellies somewhere'. This distinction is reflected in the fact that incorporated body parts in this function cannot be doubled with an external body part nominal with the same meaning (cf. (28) and (29)).

$$
\begin{aligned}
& \text { *nganam-marda-wu nanthi marda } \\
& \text { 1SGS.BE(4).NFUT-belly-lay CLF:THING belly } \\
& \text { 'I laid them in the middle (or in an object).' }
\end{aligned}
$$

There are also many examples of lexicalised functions of incorporated body parts, where the body parts have grammaticalised with the lexical stem such that it is no longer synchronically separable. One example is (34); many others involving a range of body parts are discussed by Walsh (1996).

\author{
(34a) bim-pirra-yepup $(<$ ye 'ear') \\ 1SGS.HEAR(16).NFUT-3PL.OBL-listen \\ 'I listened to them.' (RN 20091001-002:098)
}

\title{
(34b) *bim-pirra-pup
}

Thus, in the range and lexicalised functions we see semantic extensions of the meaning of incorporated body parts, as well as a change in function, whereby the incorporated body part no longer refers to an argument of the verb, but rather modifies the nature of the event being described by the verb. Differences between these functions and the external possession construction include the fact that in the latter, the incorporated body part can be doubled with an external nominal with no change in meaning (29), whereas this is not possible in the range and lexicalised constructions (33). Furthermore, in the 
external possession construction the incorporated body part always refers to a body part of the animate patient argument of the verb, whereas this is not required in range constructions as shown in (31) and (32). Lexicalised constructions are further distinguished by the fact that the original body part is no longer separable and has been synchronically reanalyzed as part of the lexical stem itself.

There are many lexicalised uses of the incorporated body part -ma- 'hand', including that in (35) below where it is used as a lexical stem meaning 'exchange'. Walsh (1996: 362) provides other examples of potential range functions for the incorporated body part, but none of these are accepted by my language consultants with the meanings he provides. My corpus contains no other clear examples of - $m a$ - in range function.

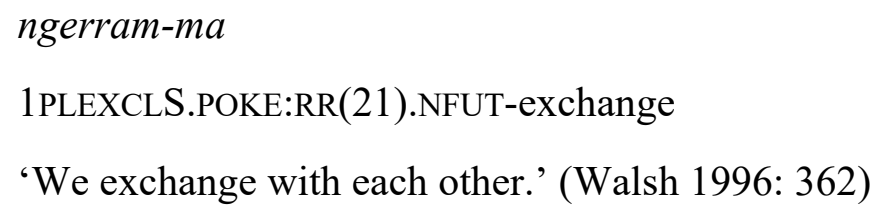

The semantic extensions in lexicalisations such as (35) are clearly related to notions of transfer and may have influenced the semantic bleaching of the incorporated body part on its path to become an applicative. However, in Section 5 I argue that there is strong evidence that the applicative construction developed from the external possession construction rather than these functions of the incorporated body part, since it is only in the external possession construction that the right morphosyntactic conditions are met to account for the development of the applicative.

\section{Applicative -ma-}

In (36a) we see the use of - $m a$ - 'hand' as an incorporated body part in an external possession construction. In this use it alternates productively with other incorporated body parts (36b) and, as we saw in Section 3, forms part of an external possession construction whereby it is interpreted as being inalienably 'possessed' by the animate object of the verb, which is encoded with the direct object marker. 
(36a) dirran-ngi-ma-thith $=$ dim

3SGS.WATCH28.NFUT-1SGO-hand-stare=3SGS.SIT(1).NFUT

'She's staring at my hands.' (RN 20090930-002:079)

(36b) dirran-ngi-me-thith $=$ dim

3SGS.WATCH(28).NFUT-1SGO-foot-stare=3SGS.SIT(1).NFUT

'She's staring at my feet.' (RN 20090930-002:079)

Since third person singular objects are unmarked in the verb, the absence of a direct object marker is interpreted as a third singular possessor, as in (37). Note that this example can only describe a situation where the subject stared at someone else's hands; it cannot mean 'She stared at her own hands' since this would require a reflexive construction (as in (28) above).

\section{(37) dirran-ma-thith $=$ dim}

3SGS.WATCH(28).NFUT-hand-stare=3SGS.SIT(1).NFUT

'She i's staring at his/her ${ }_{j}$ hands.' (RN 20090930-002:079)

The focus of this paper is another use of $-m a$ - which looks similar to the incorporated body part on the surface, but can be shown to be a distinct applicative construction. This is shown in (38b). In (38b) we appear to have the same incorporated body part 'hand', but with some important constructional differences. Firstly, as the contrast with (38a) shows, in (38b) the argument encoded by the 2 SG object marker - nhi- is not the theme of the transitive verb, but rather the source or location from which the money was collected. Thus, (38b) does not mean 'I collected your hands', as we might expect in parallel with the examples in (36) above, but rather 'I collected it from you'.

(38a) nganam-kut

1SGS.BE(4).NFUT-collect

'I collected (the money).' (RN 20070608-002:037) 
(38b) nganam-nhi-ma-kut

1SGS.BE(4).NFUT-2SGO-APPL-collect

'I collected (the money) from you.' (RN 20070608-002:037)

Furthermore, the valence of the verb in (38b) is different to that in (38a): in the regular transitive verb (38a), there are two semantic arguments: the agent (the collector) and the theme (that which is collected). In (38b) there is a third semantic argument - the source from whom the theme is collected - and it is this argument that is cross-referenced with the object marker. Although third singular objects are unmarked, (38a) cannot mean 'I collected (the money) from him/her' unless - $m a$ - is also present, as in (39):

nganam-ma-kut

1SGS.BE(4).NFUT-APPL-collect

'I collected (the money) from him/her.' (RN 20070608-002:037)

Street (1987) describes this - $m a$ - as a 'source' marker and makes no particular connection with the incorporated body part 'hand'. I argue, however, that it is an applicative that has grammaticalised from the incorporated body part 'hand', and which promotes the adjunct role 'animate source' to direct object. In the remainder of this section, I will present the evidence for this claim.

As defined by Peterson (2006: 1): “Applicatives are a means some languages have for structuring clauses which allow the coding of a thematically peripheral argument or adjunct as a core-object argument. Such constructions are signalled by overt verbal morphology". As we will see in the discussion below, the applicative use of - $m a$ - in Murrinhpatha meets these and the following morphosyntactic criteria, establishing it as a true applicative distinct from the use of - $m a-$ as an incorporated body part:

(i) the addition of - $m a$ - in the verb allows for a 'source' adjunct to be encoded as a direct object argument; 
(ii) the valency of the base verb is increased through the addition of the applicative object;

(iii) the applicative object behaves like a direct object morphologically (including overt NPs);

(iv) the applicative object can feed other morphosyntactic operations that affect objects (e.g. reflexive/reciprocal);

(v) the applicative construction can be distinguished from the incorporated body part construction on morphosyntactic and semantic grounds.

The majority of applicative examples in the corpus involve base transitive verbs which entail transfer of possession or location of a theme argument, with the animate source represented as the applicative object. As shown clearly in (38) and the examples below, the applicative object is always encoded with the object marker in the verb (or lack of, in the case of 3SG applicative objects); thus, it is treated morphosyntactically as an object and not an oblique (see Table 2 and the discussion in Section 2). Furthermore, in all of these cases, the object marker does not encode the patient/theme of the verb, but an animate source. Thus (40b), for example, does not mean 'he sent me' or 'he sent my hand', but rather 'he sent something from me'.

(40a) ngurdan-thuk

1SGS.SHOVE(29).NFUT-send

'I sent it (e.g. letter)' (RN 20070608-002:037)

(40b) wurdan-ngi-ma-thuk

3SGS.SHOVE(29).NFUT-1SGO-APPL-send

'He sent it from me.' (RN 20070608-002:037)

(40c) ngurdan-ma-thuk

1SGS.SHOVE(29).NFUT-APPL-send

'I sent it from him.' (RN 20070608-002:037) 
The examples in (41) show a similar set of contrasts with a different verb. This verb doesn't take human direct objects in its base transitive form (41b), showing clearly that it is only by virtue of the presence of applicative - $m a$ - in (41c) that the use of the direct object marker (encoding animate source) is licensed.

\author{
(41a) mangan-art kura \\ 1SGS.SNATCH(9).NFUT-get CLF:WATER \\ 'I got (some) water.' (RN 20091001-002:094) \\ (41b) *mangan-nhi-art \\ 1SGS.SNATCH(9).NFUT-2SGO-get \\ Attempted: 'I got you.'
}
(41c) mangannhimart kura
mangan-nhi-ma-art kura
1SGS.SNATCH(9).NFUT-2SGO-HAND-get CLF:WATER

'I took some water from you.' (RN 20091001-002:094)

The base object of the transitive verb (usually the patient/theme) remains as a secondary (unmarked) object in the applicative construction, showing that the base verb has increased its valency by one through the addition of the argument introduced by $-m a-$. In (41c) we see it represented with an external unmarked NP.

In the examples of the applicative construction presented above there is a clear semantic connection with the incorporated body part meaning 'hand', albeit metonymic. Example (41c) for example, could literally mean something like 'I took some water from your hand', with the semantics of source simply a metonymic extension from the incorporated body part construction. However, there are many examples where there is no semantic relationship to 'hand' at all, showing the applicative use of - $m a$ - to be truly grammaticalised. Consider the following examples of the verb 'hear/listen'. 
(42a) binthepup

bim-yepup

1SGS.HEAR(16).NFUT-listen

'I heard it' (RN 20091001-002:098)

(42b) bim-pirra-yepup

1SGS.HEAR(16).NFUT-3PL.OBL-listen

'I listened to them.' (RN 20091001-002:098)

(42c) *bim-pun-yepup (bimpunthepup)

1SGS.HEAR(16).NFUT-3PLO-listen

(42d) bim-pun-ma-yepup

1SGS.HEAR(16).NFUT-3PLO-APPL-listen

'I heard (the story) from them.' (RN 20091001-002:098)

Examples (42a) and (42b) illustrate the non-derived argument structures. In (42a) we see the standard bivalent use in which the perceiver is encoded as the subject, and the stimulus (e.g. noise, sound) as object (here unmarked, since it is third singular). Example (42b) shows another option in which the (human) source of the sound is encoded with the oblique marker. A direct object marker is not licensed by the base transitive verb, as shown by the ungrammaticality of (42c). However, in (42d) we see that the addition of the applicative licenses the object marker encoding animate source, as we would expect. The semantics of this verb, however, makes it clear that there is no semantic relationship with the incorporated body part 'hand', even metonymic, showing the original incorporated body part to be fully grammaticalised as an applicative.

This applicative construction is also possible, although less frequent, with intransitive verbs. In this case, the applied object is still interpreted as the animate source, but there is no transfer of location involved: 
(43a) ngennham

ngem-nham

1SGS.POKE:RR(22).NFUT-fear

'I'm afraid.' (RN 20070608-002:036)

(43b) *ngem-nhi-nham

1SGS.POKE:RR(22).NFUT-2SGO-fear

Attempted: 'I'm afraid of you'

(43c) ngennhimanham

ngem-nhi-ma-nham

1SGS.POKE:RR(22).NFUT-2SGO-APPL-fear

'I'm afraid of you.' (RN 20070608-002:036)

Example (44) shows that this verb cannot occur with incorporated body parts, so there is no possible analysis of (43c) that would treat the $-m a$ - as an incorporated body part rather than an applicative.

\section{(44) *ngem-me-nham}

1SGS.POKE:RR(21).NFUT-foot-fear

Attempted: 'I'm frightened of his foot.' (RN 20070608-002:036)

We have seen above strong evidence that - $m a$ - is a true applicative in that it introduces a non-argument into direct object position, and therefore increases the valency of the verb. This meets all standard definitions of applicatives, including the following from Polinsky (2013: 1): "In an applicative construction, the number of object arguments selected by the predicate is increased by one with respect to the basic construction". Evidence that the applicative object in these -ma-constructions is really an object argument comes from the fact that it can feed reflexive and reciprocal constructions, as shown in the following examples. 
pam-ngintha-nu-ma-rartal

3SGS.SLASH:RR(24).NFUT-DU.F-RR-APPL-cut.off(RDP)

'They tore the cloth from each other.' (RN 20070531-002:011)

(46) them-nu-ma-nham

1INCLS.POKE:RR(21).NFUT-RR-APPL-fear

'We're (inclusive) frightened of each other.' (RN 20070608-002:036)

(47) bim-nu-ma-yepup $=$ ngem

1SGS.HEAR(16).NFUT-RR-APPL-listen=1SGS.SIT(1).NFUT

'I'm listening to myself on tape [Lit. I'm hearing (the story) from myself].'

(RN 20091001-002:098)

The applicative construction in Murrinhpatha is not obligatory - an animate source can alternatively be expressed with an external locative PP in which case it is not encoded on the verb and does not function as a direct object. Example (48) shows the alternation between the two options: in (48a) the animate source is expressed as an external PP adjunct with an underived transitive verb; in (48b) the applicative construction is used.

(48a) nanthi

mangan-art

ngarra ngay

CLF:THING 3SGS.SNATCH(9).NFUT-get LOC 1SG

'He got it from me.' (RN20070608-002:035)

(48b) nanthi mangan-ngi-ma-art

CLF:THING 3SGS.SNATCH(9).NFUT-1SGO-APPL-get

'He got it from me.' (RN20070608-002:035)

While the primary function of this applicative construction is to promote an animate source to direct object, depending on context this construction can also be used to encode possessors/maleficiaries as shown in (49) and (50). This is a common 
semantic extension crosslinguistically (e.g. Quint 2010). The contrast between (50) and (51) shows clearly the semantic contribution of the applicative construction: in the underived (51) the direct object marker encodes the patient of the hitting event ('he hit me') whereas in the applicative example in (50) the same direct object marker expresses the animate source/possessor of the patient ('he hit my truck').

$\begin{array}{lll}\text { Ba-nhi-ma-gurduk-ngadha } & \text { kura } & \text { burrburr } \\ \text { 1SGS.SEE(13).FUT-2SGO-APPL-drink-EVEN } & \text { CLF:WATER } & \text { cold }\end{array}$

'I'm going to have a drink of your cold water.' (RN 20091001-002:100)

OR 'I'm going to drink cold water from you.'

nanthi truck pan-ngi-ma-bat thu

CLF:THING truck 3SGS.SLASH(23).NFUT-1SGO-APPL-hit CLF:WEAPON

lithpurr-re

axe-AGT

'He hit my truck with an axe.' [Lit: 'He hit a truck from me with an axe'] (RN 20091001-002:091)

$(51)$
pan-ngi-bat
thu
lithpurr-re
3SGS.SLASH(23).NFUT-1SGO-hit
CLF:WEAPON axe-AGT

'He hit me with an axe.' (RN 20091001-002:091)

These possessive uses always have a malefactive sense rather than a benefactive sense. Benefactive meanings are expressed with non-applicative verbs in Murrinhpatha, with the use of the oblique marking on the verb, as discussed in Section 2 and shown in (13)-(15) above - (13) is also repeated here as (52).

(52) ngina-mpa-thi-nu

1SGS.HEAT(27).FUT-2SG.OBL-cook-FUT

'I'll cook it for you.' (RN 20070608-002:042) 
The following example illustrates these two construction types. In the first clause we see the applicative, with the source argument denoted by the object marker and the applicative - $m a$ - added to the verb. In the second clause, there is no - $m a-$, and the oblique marker is used to encode the benefactive (note that -bert-and-berti-are two distinct stems).

$\begin{array}{lll}\text { ma-nhi-ma-bert-nu} & i & \text { nakurl-wangu } \\ \text { 1SGS.HANDS(8).FUT-2SGO-APPL-grab-FUT } & \text { and } & \text { later-AWAY } \\ \text { ma-mpa-berti-nu } & & \end{array}$

1SGS.HANDS(8).FUT-2SG.OBL-take.person-FUT

'I'll take (the baby) from you and I'll bring him back to you later.' (RN, MP20100920-RN01)

Examples such as (42)-(44) above establish that the applicative - $m a$ - is distinct from the incorporated body part - $m a$ - 'hand' since (i) the applicative can be used in contexts where the semantics of 'hand' (and metonymic extensions) are inappropriate, as in (42); and (ii) the applicative can be used with verbs that do not usually combine with incorporated body parts, as shown in (43) and (44). Another difference between the incorporated body part and the applicative is that the former can be doubled by an external nominal, but the latter cannot. This contrast is shown in (54):

(54a) mange mem-ma-yeth

hand 3SGS.HANDS:RR(10).NFUT-hand-cut

'He cut his hand.' (RN 20070530-002:005)

(54b) *mange pumanganngimart

mange pumangan-ngi-ma-art

hand 3PLS.SNATCH(9).NFUT-1SGO-APPL-get

Attempted: 'They took it from me.' [Could only be interpreted as the semantically anomalous 'They took the hand from me.'] (RN 20070608002:036) 
Thus, applicative -ma-constructions in Murrinhpatha have all of the morphosyntactic properties we would expect of applicative constructions and can be clearly distinguished from the use of - $m a$ - as an incorporated body part. Of course, it's entirely possible that the homophony in form between applicative -ma- and the incorporated body part 'hand' is purely coincidental, and that the two grammatical elements are not related to each other. In the next section I argue that, on the contrary, there is strong evidence that the applicative use has grammaticalised from the incorporated body part through the external possession construction.

\section{From 'hand' to 'source'}

There is plenty of evidence that the applicative $-m a$ - is related to the incorporated body part 'hand'. Firstly, other languages of the Daly River region, namely Marrithiyel (Green 1989) and Ngan'gityemerri (Reid 1990; 2000) have also been described as having applicative markers that are formally related to incorporated body parts, although the details are different in some respects to what we have seen in Murrinhpatha.

In Ngan'gityemerri, Murrinhpatha's closest relative, there is a comitative applicative - $m i$ - deriving from the incorporated body part 'eye'. This applicative promotes a comitative NP to a direct object, as shown in the following examples (Reid 1990):
(55a) ngaganiny-wap
1SGS.GO.PFV-sit
'I sat down'.

(55b) ngaganiny-nyi-mi-wap

1SGS.GO.PFV-2SGO-APPL-sit

'I sat down with you'.

A similar comitative applicative marked with - $m i$ ('eye') is also found in Marrithiyel, (Western Daly). In Marrithiyel there are two further applicative markers derived from 
incorporated body parts: -ma- ('belly') which derives a causative of emotion (e.g. ma-lerri (APPL-happy) 'make (OBJ) happy'), and -mu- ('hand') which derives an applicative encoding transfer of location, very similar to what we have seen for Murrinhpatha (56) (Green 1989: 290):

(56) wiyan $\quad$ ngurr-inj-mu-duk-wa
tobacco $\quad$ 1SGS.IRR.RR-2SGO-APPL-remove-FUT
'I'll take your tobacco off you.' (Green 1989: 290 ex. 5-173.b)

The existence of applicatives that have developed from incorporated body parts in other languages of the surrounding Daly region strengthens the claim that applicative -ma- in Murrinhpatha has grammaticalised from the incorporated body part 'hand', especially given that Marrithiyel is reported as having a similar applicative with the same function. Ngan'gityemerri and Marrithiyel are reported as having other applicatives formed from body parts meaning 'eye' and 'belly', but it is not clear whether these exist in Murrinhpatha as well. There are a few examples which are suggestive of a locative applicative use of -ngka- 'eye', but the data is not sufficient at this stage to determine whether this is a productive or a lexicalised usage. ${ }^{10}$

kardu kani-ngi-ngka-thek-nu-kama

CLF:HUMAN 3SGS.BE(4).FUT:IRR-1SGO-eye-defecate-FUT-MAYBE

'The child might defecate on me!' (Mansfield 2019: 210)

kanam-ngi-ngka-be

3SGS.BE(4).NFUT-1SGO-eye-spit

'He spat on me' (LP, 2015-07-05_AM, Mansfield, pers. comm.)

Further evidence that the - $m a$ - applicative has developed from the incorporated body part is the fact that they share the same slot in the verbal template (Table 1) and cannot co-occur.

\footnotetext{
${ }^{10}$ I am grateful to John Mansfield for drawing my attention to these examples.
} 
I argue that the applicative use of $-m a$ - has grammaticalised directly from the incorporated body part use, via the external possession construction. As we will see, external possession constructions provide the appropriate structural context for the development of the applicative since they have (i) a human affected participant encoded with the direct object marker (the possessor); and (ii) a second object element that can be expressed with an external nominal (the body part). Thus, they provide the template for the increased-valency required by an applicative construction. Gerdts and Hinkson (2004) present a similar argument in their analysis of the grammaticalisation of the lexical prefix meaning 'face' into a dative applicative in Halkomelem. They suggest that the applicative use has developed out of the external possession construction which provides the required morphosyntactic frame, but influenced also by the bleached semantics of the classifier function of the lexical prefix (pp. 242-243).

The analysis presented here also accounts for the unusual semantics of the Murrinhpatha applicative construction which, as we have seen, covers the semantics of animate source and possessor/maleficiary. I will argue that the source meaning for the applicative has developed out of external possession constructions with a particular set of transfer verbs (59). The fact that the source has to be animate follows from the fact that the applicative arises from an external possession construction with the incorporated body part 'hand', and the possessor of 'hand' will always be animate. It is not unusual cross-linguistically to find source meanings extend to maleficiary (e.g. Quint 2010), and for maleficiary meanings to be associated with possessors (e.g. Baker 1996), thus accounting for the range of meanings of the Murrinhpatha applicative shown in (60)-(61).

ngungu-nhi-ma-rurr-nu

1SGS.32.FUT-2sGO-hand-pull.from-FUT

'I'll pull (the splinter) out of your hand.' (RN 20091001-002:094)

(60) nanthi truck pan-ngi-ma-bat thu
CLF:THING truck 3SGS.SLASH(23).NFUT-1SGO-APPL-hit CLF:WEAPON
lithpurr-re
axe-AGT


'He hit my truck with an axe' (RN 20091001-002:091)

(61)

pumanganngimart

pumangan-ngi-ma-art

3PLS.SNATCH(9).NFUT-1SGO-APPL-get

'They took it from me.' (RN 20070608-002:036)

There are two steps to the analysis to be presented here. Firstly, we need to establish a bridging context which could lead to the reanalysis of an external possession construction as an applicative meaning 'animate source'. Secondly, we need an explanation for why it would be the body part 'hand' that is reanalysed in this way.

A bridging context for the reanalysis of external possession constructions as encoding animate source comes from verbs of transfer, which allow for an alternative argument structure in which an animate participant is interpreted as source. This includes verbs such as (classifier $32+$ ) -pirt 'remove' and (classifier $32+$ ) -rurr 'pull', which alternate between basic agent-theme argument frames ('remove OBJ', 'pull OBJ') and those in which the source of the transfer is encoded as object 'remove from OBJ', 'pull from OBJ'. Consider the examples in (62):

(62a)

$\begin{array}{lll}\text { yungan-ngi-rurr } & \text { nanthi } & \text { pi } \\ \text { 3SGS.32.NFUT-1SGO-pull } & \text { NC:THING } & \text { undertow }\end{array}$

'The undertow pulled me under.' (RN MP-20091008-RN01)

(62b)
yungan-rurr
nanthi
pi
3SGS.32.NFUT-pull
NC:THING undertow

'The undertow pulled him under.' (RN MP-20091008-RN01)

(62c) yungan-ngi-we-rurr

3SGS.32.NFUT-1SGO-hair-pull

'He pulled my hair (to get me out of the water).' (RN MP-20100916-RN01) 
1SGS.32.FUT-2sGO-foot-pull.from-FUT

'I'll pull (the splinter) out of your foot.' (RN 20091001-002:094)

In (62a) and (62b) the verb has a standard agent-patient argument structure with the object marker in (62a) referring to the patient of the verb, 'me'. In (62b) there is no object marker, as expected since the patient is third singular. In (62c), the external possession construction, the patient of the verb is 'hair' and the object marker refers to the 'possessor' of the hair, but the basic thematic relations encoded in the verb's argument structure remain the same. In the external possession construction in (62d), on the other hand, the object marker (plus incorporated body part) refers to the animate source from which the (unexpressed) theme is pulled. (62d) in this context does not mean 'I'll pull your foot', but rather 'I'll put something from your foot'. In this case, the object marker is interpreted as encoding the 'animate source' from where something is pulled as part of a regular external possession construction.

The examples in (63) show a similar use of the verb (classifier $32+$ ) -pirt 'remove (from)'. These come from a spontaneous interaction where the speaker was joking with another participant that she wanted to "steal" all of her jewellery:

(63a) ngungu-nhi-ma-wirtpirt-nu

1SGS.32.FUT-2sGO-hand-remove.from(RDP)-FUT

'I'll take all your (rings) off.' [Lit. I'll remove (them) from your hands] (RN 20091001-002:093)

(63b) ngungu-nhi-ye-pirt-nu

1SGS.32.FUT-2SGO-ear-remove.from-FUT

'I'll take your (earrings) off.' [Lit. I'll remove (them) from your ears] (RN 20091001-002:093)

\footnotetext{
${ }^{11}$ A reviewer asks whether it would be possible to have an external nominal here referring to 'foot'. The analysis I am presenting assumes that it would be possible, as it is with all external possession constructions. However, unfortunately the present corpus does not include a relevant example with this verb to establish this definitively.
} 
(63c) ngungu-nhi-be-wirtpirt-nu

1SGS.32.FUT-2SGO-arm-remove.from(RDP)-FUT

'I'll take your (watch) off.' [Lit. I'll remove (it) from your arm]

(RN 20091001-002:093)

The speaker then ends with the following, which illustrates exactly the bridging context we need to motivate the development of the applicative use. In this example, the incorporated body part - $m a$ - 'hand' has undergone a metonymic shift, now indicating the entire participant as a source, rather than the specific body part:

$\begin{array}{lll}\text { ngani-nhi-ma-kut-nu} & \text { nanthi } & \text { terert! } \\ \text { 1SGS.BE(4).FUT-2SGO-APPL/hand-collect-FUT } & \text { CLF:THING } & \text { many }\end{array}$

'I'll take everything from you!' (RN 20091001-002:093)

In (64) we see the use of the -ma- 'hand' incorporated body part, in this case apparently referring to the whole person, as in 'I'll take everything from your body/all of you'. This semantic extension is consistent with the common grammaticalisation path HAND > LOCATION identified by Heine and Kuteva (2002: 166), and moreover there is language-internal evidence for this semantic extension from 'hand' to 'whole person' that accounts for why the incorporated body part in (64) might be possible in this context.

Firstly, the external nominal mange 'hand' is used in a lexicalised phrase meaning '(by) oneself' in conjunction with the relevant pronoun, as shown in (65):

mange ngay ngunungam $=$ ngem

hand $1 \mathrm{SG} \quad$ 1SGS.FEET(7).NFUT=1SGS.SIT(1).NFUT

'I'm going by myself.' (Street \& Street 1989, \#mange ngay)

(66) $m i$

kanam-murk mange nigunu

CLF:VEG 3SGS.BE(4).NFUT-eat hand 3SG.F

'She's eating it herself.' (RN MP-20100920-RN01) 
Mange 'hand' is also used to talk about a person's 'acts' or 'ways', as in the following examples from the Murrinhpatha-English legal glossary (Ford \& McCormack 2011):

\begin{tabular}{|c|c|c|c|c|}
\hline$v u$ & bethpirr, & $n g a y-k a$ & ngamam & mange-yu \\
\hline yes & indeed & $1 \mathrm{SG}-\mathrm{TOP}$ & 1SGS.SAY/DO(34).NFUT & hand-CLS \\
\hline
\end{tabular}

'Yes, indeed, I have done those acts.' (\#Guilty Plea)

(68) kanhi-ka murrinh ngarramange kardu bamam-nukun this-TOP CLF:LANG REL hand CLF:HUMAN white-POSS 'These are the words which belong to the way of non-Aboriginal people.' (\#Australian law)

Furthermore, there is a homophonous affix, described by Walsh (1976: 183) and Street (1987) as the comitative or 'having' affix, that is used with nominals in attributive or associative function, as in the examples below.

(69) palngun kamal-ma

woman eye-COM

'a woman with good eyesight' (Walsh 1976:184)

(70) kardu thungku-ma

CLF:HUMAN fire-COM

'a person habitually associated with fire' (Walsh 1976:188)

Such nouns also carry object markers indicating the person and number of the referent they are predicated of, as seen clearly once the referent is not third person singular:

(71) palngun-nhi-ma?

woman-2SGO-COM

'Do you have a wife?' (Mansfield 2019: 166) 
Mansfield (2019) suggests that this use of - $m a$ - may in fact be the applicative function, the same as what we have seen with verbs above. However, it is not clear that $-m a$ - in this nominal function actually promotes an oblique participant to the role of direct object, as we would expect of a true applicative, since the argument structure in (71) appears no different to that in the regular nominal phrases involving body parts, such as those given in (72)-(74):

\author{
(72) thakunh-ngi-ma \\ left-1SGO-hand \\ 'I'm left-handed' (Street \& Street 1989 \#thakunh)
}

In fact, it is common for incorporated body parts to be added to nominals in this way, attributing the semantic properties of the nominal to a particular body part, and in these examples, the $-m a$ - 'comitative' is not required:

pemarr-ngi-we

hair-1SGO-head

'I have a lot of (head) hair.' (Walsh 1976:182)

(74)

net-ngi-ngka

boil-1SGO-face

'I have a boil on my face.' (Walsh 1976:182)

Furthermore, the use of - $m a$ - with nominals is not associated with the meaning of 'source' as it is in the applicative use. Thus, I suggest that the use of -ma-in examples such as (71) is not an example of the applicative function per se, but rather another instance of the semantic extension of 'hand' to refer to the whole person, as we see with the nominal mange in (67) and (68). Thus, (71) is the same construction as (72)(74) and is a metonymic extension of 'I have a woman (in) my hand'. It is this semantic relationship between 'hand' and 'whole person' which enables the reanalysis of the incorporated body part $-m a$ - in external possession constructions 
such as (63a) as a true applicative, as exemplified in examples such as (75), repeated from (42d) above:

bim-pun-ma-yepup

1SGS.HEAR(16).NFUT-3PLO-APPL-listen

'I heard (the story) from them.' (RN 20091001-002:098)

Thus, the development from incorporated body part 'hand' to the animate source applicative marker can be seen to have proceeded in the following way:

(i) The external possession construction licenses the co-occurrence of the incorporated body part with a direct object marker referring to an animate affected participant (e.g. yungan-ngi-ma-rurr 'He pulled my hand' (3SGS.32.NFUT-1SGO-hand-pull));

(ii) Transfer of location verbs with alternative argument frames allow for the interpretation of the incorporated body part + direct object marker as source rather than theme/patient ('from/associated with my hand') (e.g. yungan-ngi-ma-rurr 'He pulled it from my hand' (3SGS.32.NFUT-1SGOhand-pull));

(iii) The semantic extension from 'hand' to 'whole person' found more generally in the language allows for the bleaching of the body part meaning so that - $m a$ - refers to the whole not the part ('from/associated with you') (e.g. 'I will remove it from you' (64));

(iv) This then enables reanalysis as a source applicative which functions to add an animate source direct object to verbs for which this is not part of the base argument structure (e.g. 'I will drink water from you' (49)).

\section{Conclusion}

In the above discussion I have shown that the incorporated body part -ma- 'hand' in Murrinhpatha has grammaticalised into an applicative marker which promotes an animate source to object. This grammaticalisation was licensed by the external possession construction combined with a semantic extension from 'hand' to the whole 
person associated with the body part. This has therefore led to the reanalysis of ' $\mathrm{X}$ 's hand' > 'something associated with X' > 'from X (being a person)' and 'negatively affecting $X^{\prime}$ (maleficiary function).

Peterson (2006), in his typological study of applicative constructions, claims that the primary sources for applicatives cross-linguistically are adpositional and verbal (p. 170), and he states that "[c]laiming that an applicative marker derives from a noun source ... is inherently problematic since in general it is impossible to show that a noun has not gone through an intermediate adpositional stage (as body parts are wont to do) on its way to becoming an applicative marker" (Peterson 2006: 141). Craig and Hale (1988: 343) mention Warlpiri as a possible example in which applicatives may have developed from nominal sources, but Peterson (2006: 127) suggests that the nominal may have first developed an adpositional use, which then developed into the applicative, meaning that the applicative development was not from the noun directly.

The analysis presented in this paper argues that the source applicative in Murrinhpatha has developed directly from the incorporated body part, and not from an adpositional use. This does not constitute a counter-example to Peterson's (2006) claim that applicatives don't develop directly from nouns since the Murrinhpatha applicative has developed from a related bound element and not from the noun itself. However, it does extend the grammaticalisation sources for applicative constructions beyond verbal and adpositional ones, and therefore makes a useful contribution to our typology of applicative constructions and their development (see Peterson 2006:141). The unusual semantics of the Murrinhpatha applicative can be seen to have resulted from its atypical source in an incorporated body part meaning 'hand'.

The development of this applicative out of an incorporated body part construction, and not from a more typical verbal or adpositional source, further supports similar claims made in the literature such as by Gerdts and Hinkson (2004), who discuss the development of a dative applicative marker from a lexical suffix meaning 'face' in Halkomelem, and Bugaeva (2010), who argues that two applicative markers in Ainu appear to originate in nouns meaning 'head' and 'bottom'.

The development of applicatives from incorporated body parts appears to be an areal pattern of grammaticalisation in the Daly River region of Australia, and it remains for further work to extend this analysis to the developmental paths of other 
applicative markers from body parts in Ngan'gityemerri, Marrithiyel and potentially other cases in Murrinhpatha as well. Nonetheless it is clear that we need to expand our typologies to account for the development of applicative markers directly from incorporated body parts. This work also highlights the value in exploring the complex verbal constructions of polysynthetic languages - where morphs with a range of grammatical and derivational functions can be found interspersed within a tightly bound morphological structure - to inform our understanding of grammaticalisation possibilities.

\section{Acknowledgements}

The argument and analysis presented in this paper was first presented in conference papers at the European Australianist meeting in Leiven (2009) and the Association for Linguistic Typology conference in (2011), and I thank audiences of those presentations for useful feedback that has helped to strengthen and refine it. I am extremely grateful to Francella Bunduck, Bill Forshaw, John Mansfield and Joe Blythe for contributing data, and especially to Carmelita Perdjert and the other speakers of Murrinhpatha who have worked with me over many years and have contributed the bulk of the data on which this analysis is based. I am also appreciative of the comments and suggestions of Masha Koptjevskaja Tamm and four Linguistic Typology reviewers which lead to substantial improvements in argumentation and presentation. This research has been funded by the ARC Centre of Excellence for the Dynamics of Language (Project ID: CE140100041), and through ARC Discovery Projects DP110100961 and DP0984419.

\footnotetext{
Abbreviations

The following abbreviations are used in the glosses: AGT 'agentive suffix', APPL 'applicative', CLF 'noun classifier', CLS 'clause-final discourse marker', COM 'comitative suffix', DU 'dual', EXCL 'exclusive', F ‘feminine', FUT 'future', INCL 'inclusive', IRR ‘irrealis mood', LOC 'locative', M 'masculine', NFUT 'non-future', O 'object', OBL 'oblique', PFV 'perfective', PC 'paucal', PL 'plural', POSS 'possessor', RCGN 'recognitional demonstrative', RDP 'reduplicated', REL 'relative clause marker', RR 'reflexive/reciprocal', $S$ 'subject', SG 'singular', TEMP 'temporal affix', TOP 'topic
} 
marker'. Classifier stems are glossed with their traditional number (Blythe, Nordlinger \& Reid 2007) and an indicative semantic gloss wherever possible.

\section{References}

Baker, Brett, Kate Horrack, Rachel Nordlinger \& Louisa Sadler. 2010. Putting it All Together: Agreement, Incorporation, Coordination and External Possession in Wubuy (Australia). In Miriam Butt \& Tracy Holloway King (eds.), Proceedings of LFG10, 64-84. Stanford, CA: CSLI Publications.

Baker, Mark C. 1996. The polysynthesis parameter. Oxford University Press.

Beaver, John. 2011. On affectedness. Natural Language \& Linguistic Theory 29(2). $335-370$.

Blythe, Joe. 2013. Preference Organization Driving Structuration: Evidence from Australian Aboriginal Interaction for Pragmatically Motivated Grammaticalization. Language 89(4). 883-919. doi:10.1353/lan.2013.0057.

Blythe, Joseph. 2009. Doing referring in Murrinh-Patha conversation. University of Sydney.

Blythe, Joseph, Rachel Nordlinger \& Nick Reid. 2007. Murriny Patha finite verb paradigms. Wadeye, NT, ms.

Bowern, Claire. 2014. Complex predicates in Australian languages. In Harold Koch \& Rachel Nordlinger (eds.), The Languages and Linguistics of Australia: a comprehensive guide, 263-294. Berlin: Mouton de Gruyter.

Bugaeva, Anna. 2010. Ainu applicatives in typological perspective. Studies in Language 34(4). 749-801.

Chappell, Hilary \& William McGregor (eds.). 1996. The Grammar of Inalienability: A Typological Perspective on Body Part Terms and the Part-Whole Relation. Berlin: Mouton de Gruyter.

Craig, Colette Grinevald \& Ken Hale. 1988. Relational preverbs in some languages of the Americas: Typological and historical perspectives. Language 64. 312-343.

Evans, Nicholas. 2017. Polysynthesis in Northern Australia. In Michael Fortescue, Marianne Mithun \& Nicholas Evans (eds.), The Oxford Handbook of Polysynthesis, 312-335. Oxford: Oxford University Press. 
Fleck, David W. 2006. Body-Part Prefixes in Matses: Derivation or Noun Incorporation? International Journal of American Linguistics 72(1). 59-96. doi:10.1086/505279.

Ford, Lysbeth \& Dominic McCormack. 2011. Murrinhpatha-English legal glossary. Batchelor, N. T.: Batchelor Press.

Forshaw, William. 2011. A continuum of incorporation: noun incorporation in Murrinh-Patha. University of Melbourne Honours thesis.

Fortescue, Michael, Marianne Mithun \& Nicholas Evans. 2017. Introduction. In Michael Fortescue, Marianne Mithun \& Nicholas Evans (eds.), The Oxford Handbook of Polysynthesis, 1-16. Oxford: Oxford University Press.

Gerdts, Donna B. \& Mercedes Q. Hinkson. 2004. The Grammaticalization of Halkomelem 'Face' into a Dative Applicative Suffix. International Journal of American Linguistics 70(3). 227-250. doi:10.1086/425600.

Green, Ian. 1989. Marrithiyel: a language of the Daly River region of Australia's Northern Territory. Canberra: ANU PhD dissertation.

Green, Ian. 2003. The genetic status of Murrinh-patha. In Nicholas Evans (ed.), The Non-Pama-Nyungan languages of Northern Australia, 125-158. Canberra: Pacific Linguistics.

Harvey, Mark. 1996. Body parts in Warray. In Hilary Chappell \& William McGregor (eds.), The Grammar of Inalienability: A Typological Perspective on Body Part Terms and the Part-Whole Relation, 111-154. Berlin: Mouton de Gruyter.

Heine, Bernd \& Tania Kuteva. 2002. World lexicon of grammaticalization. Cambridge: Cambridge University Press.

Mansfield, John. 2014. Polysynthetic sociolinguistics: the language and culture of Murrinh Patha Youth. https://digitalcollections.anu.edu.au/handle/1885/12687 (3 December, 2015).

Mansfield, John. 2016. Intersecting formatives and inflectional predictability: How do speakers and learners predict the correct form of Murrinhpatha verbs? Word Structure 9(2). 183-214.

Mansfield, John. 2019. Murrinhpatha words: morphology and phonology. Berlin: de Gruyter Mouton.

Mansfield, John \& Rachel Nordlinger. In Press. Deepening complexity in recent changes to Murrinhpatha inflectional paradigms. In Peter Arkadiev \& 
Francesco Gardani (eds.), Morphological complexity, xxx-xxx. Oxford: Oxford University Press.

McGregor, William B. 2002. Verb classification in Australian languages. Berlin: Mouton de Gruyter.

Mithun, Marianne. 2001. The difference a category makes in the expression of possession and inalienability. In Irene Baron, Michael Herslund \& Finn Sørensen (eds.), Dimensions of possession, 285-310. Amsterdam: John Benjamins.

Mithun, Marianne. 2017. Argument marking in the polysynthetic verb and its implications. In Michael Fortescue, Marianne Mithun \& Nicholas Evans (eds.), The Oxford Handbook of Polysynthesis, 30-58. Oxford: Oxford University Press.

Mujkic, Elena. 2013. Murrinh-Patha syntax: clausal structure and the noun phrase. University of Melbourne BA Honours.

Nordlinger, Rachel. 2010. Verbal morphology in Murrinh-Patha: evidence for templates. Morphology 20(2). 321-341.

Nordlinger, Rachel. 2011. Transitivity in Murrinh-Patha. Studies in Language 35(3). 702-734.

Nordlinger, Rachel. 2015. Inflection in Murrinhpatha. In Matthew Baerman (ed.), The Oxford Handbook of Inflection, 491-519. Oxford: Oxford University Press.

Nordlinger, Rachel. 2017. The languages of the Daly River region (Northern Australia). In Michael Fortescue, Marianne Mithun \& Nicholas Evans (eds.), The Oxford Handbook of Polysynthesis, 782-807. Oxford: Oxford University Press.

Payne, Doris L. \& Immanuel Barshi (eds.). 1999. External Possession. Amsterdam: John Benjamins.

Peterson, David A. 2006. Applicative constructions. Oxford: Oxford University Press. Polinsky, Maria. 2013. Applicative Constructions. In Matthew S. Dryer \& Martin Haspelmath (eds.), The World Atlas of Language Structures Online. Leipzig: Max Planck Institute for Evolutionary Anthropology. http://wals.info/chapter/109.

Quint, Nicolas. 2010. Benefactive and malefactive verb extensions in the Koalib verb system. In Fernando Zúñiga \& Seppo Kittilä (eds.), Benefactives and 
malefactives: Typological perspectives and case studies, 295-315.

Amsterdam: John Benjamins.

Reid, Nicholas. 2000. Complex Verb Collocations in Ngan'gityemerri: A nonderivational mechanism for encoding valency alternations. In R. M. W. Dixon \& Alexandra Aikhenvald (eds.), Changing Valency: Case studies in transitivity (Studies in Language Series), 333-359. Cambridge: Cambridge University Press.

Reid, Nicholas John. 1990. Ngan'gityemerri: a language of the Daly River region, Northern Territory of Australia. Australian National Univ. Canberra.

Schultze-Berndt, Eva. 2000. Simple and complex verbs in Jaminjung. A study of event categorisation in an Australian language. Nijmegen: Dissertation, Univ. Nijmegen (MPI Series in Psycholinguistics 14).

Street, Chester. 1987. An introduction to the language and culture of the MurrinhPatha. Summer Institute of Linguistics, Australian Aborigines Branch Darwin, Northern Territory.

Street, Chester. 1996. Tense, aspect and mood in Murrinh-Patha. Studies in Kimberley Languages in Honour of Howard Coate. München: Lincolm Europe.

Street, Chester \& Lyn Street. 1989. Murrinh-Patha vocabulary. Electronic MS Word file.

Tryon, D. T. 1974. Daly family languages, Australia. Canberra: Pacific Linguistics.

Walsh, Michael. 1976. The Murinypata language of North West Australia. Canberra: Australian National University PhD dissertation.

Walsh, Michael. 1996. Body parts in Murrinh-patha: incorporation, grammar and metaphor. In Chappell Hilary \& McGregor William B. (eds.), The Grammar of Inalienability: A Typological Perspective on Body Part Terms and the PartWhole Relation, 327-380. Berlin, New York: Mouton de Gruyter.

Walsh, Michael J. 1997. Noun Classes, Nominal Classification and Generics in Murrinhpatha. Nominal Classification in Aboriginal Australia (Studies in Language Companion Series), vol. 37, 255-292. Amsterdam: John Benjamins.

Wilson, Stephen. 1999. Coverbs and Complex Predicates in Wagiman. Stanford, CA: CSLI Publications. 